\title{
The relationship between spiritual well-being, mental health and quality of life in infertile women
}

\author{
ZAHRA BEYGI1, A, F, NAMAVAR JAHROMI BAHIA 2, B, D, F, FIROOZEH NOURIMAND ${ }^{3, c, E}$, \\ ZEYNAB AMOOZANDEH ${ }^{4, B, E, F}$, SEDIGHE FOROUHARI ${ }^{5, A, E, F}$ \\ ORCID ID: 0000-0003-4399-7923
}

${ }^{1}$ Department of Midwifery, School of Nursing and Midwifery, Islamic Azad University Meybod Branch, Yazd, Iran

${ }^{2}$ Infertility Research Center, Shiraz University of Medical Sciences, Shiraz, Iran

${ }^{3}$ Vali Asr Educational Hospital, Fasa University of Medical Sciences, Fasa, Iran

${ }^{4}$ Department of Midwifery, Estahban Branch, Islamic Azad University, Estahban, Fars, Iran

${ }^{5}$ Infertility Research Center, Research Center of Quran, Hadith and Medicine, Shiraz University of Medical Sciences, Shiraz, Iran

A - Study Design, B - Data Collection, C - Statistical Analysis, D - Data Interpretation, E - Manuscript Preparation, F - Literature Search, G - Funds Collection

Summary Background. Spiritual well-being and mental health can be regarded as highly important in infertile women.

Objectives. The purpose of the present study was to investigate the relationship between spiritual wellbeing, mental health and quality of life in infertile women.

Material and methods. In this cross-sectional study, the statistical population of the study consisted of infertile women who referred to hospitals in Shiraz, among whom 247 subjects participated in the study. Paloutzian and Ellison's Questionnaire of Spiritual Well-Being, Mental Health, Quality of Life and Economic Situation was used in this study. Data was analyzed using descriptive statistics methodology, including mean and frequency in the form of tables, charts and Spearman's Correlation Tests.

Results. Mental status has a statistically significant relationship with spiritual well-being $(p=0.001)$. Mental health has a statistically significant relationship with mental status $(p=0.001)$. There was a statistically significant relationship between belief status and spiritual well-being $(p=0.001)$. The relationship between belief status and mental health was statistically significant $(p=0.001)$. There was a statistically significant relationship between economic status and belief status $(p=0.001)$. There was a statistically significant relationship observed between the quality of life and mental status $(p=0.001)$. Quality of life was seen to have a statistically significant relationship with mental health $(p=0.001)$. The results also demonstrated that quality of life has a statistically significant relationship with belief status $(p=0.01)$.

Conclusions. Well-being can help improve the mental status of infertile women. Religious beliefs can guarantee spiritual well-being, and if infertile women have appropriate mental health, their quality of life will increase.

Key words: infertility, mental health, quality of life, women.

Beygi Z, Bahia NJ, Nourimand F, Amoozandeh Z, Forouhari S. The relationship between spiritual well-being, mental health and quality of life in infertile women. Fam Med Prim Care Rev 2021; 23(4): 412-416, doi: https://doi.org/10.5114/fmpcr.2021.110353.

\section{Background}

The World Health Organization has introduced infertility as a reproductive health problem worldwide. Researchers believe that this crisis can be accompanied by considerable personal, marital, psychological, emotional and medical consequences [1, 2].

Spirituality refers to what connects people with the holy and meaningful beings beyond them. Such actions often create connections with a superpower that gives meaning to life; therefore, infertile couples who encounter complex existential issues, psychological distress and social labels may be able to cope with infertility challenges through religious practices and reach a level of comfort and relief $[3,4]$.

Around $10-15 \%$ of couples experience infertility worldwide, and in Iran, this has been reported to be about $10.9 \%[5,6]$. Diagnosis of infertility is recognized as an important clinical subject, and some researchers believe that harmful psychosocial factors play an essential and pathogenic role in the development of the disease, and some believe that these factors are significant. Numerous studies indicate that infertility leads to the emergence of psychological problems in infertile women. On the other hand, stressors can affect medical treatment as a re- sult of delaying or obstructing ovulation. Various studies have been conducted on the characteristics of infertile women, indicating that they have various psychological problems of varying degrees. In some cases, the psychological disturbances in such patients lead to suicidal thoughts after unsuccessful treatments. According to the majority of researchers, infertile people experience more stress than fertile individuals. Negative effects of infertility stress are remarkably higher in women than in men; they are more anxious and depressed with lower levels of self-esteem and have weaker coping skills and quality of life $[7,8]$. Studies indicate that infertile women showed a significant difference in all the parameters of hospital depression and anxiety, including stress, hostility, anxiety, depression and self-blame compared to fertile women. The consequences of these psychosocial and mental traumas result in that $10 \%$ of infertile women develop suicidal thoughts [9]. In a study, the effects of infertility on sexual-psychiatric disorders were examined in 150 Iranian women over a period of 4 months. The results demonstrated that $24.6 \%$ of them had no symptoms of depression, $30 \%$ had symptoms of mild depression, $32 \%$ had symptoms of moderate depression, and $13 \%$ had severe symptoms of depression [10].

Spirituality and religious beliefs refer to what connects people to the holy and meaningful beings beyond them. Such 
actions often create connections with a superpower that gives meaning to life; therefore, infertile couples who encounter complex existential issues, psychological distress and social labels may be able to cope with infertility challenges through religious practices and reach a level of comfort and relief [3, 4]. Although research studies have demonstrated that religion and spirituality can be highly valuable for many people during periods of crisis, trauma and grief, various studies indicate that few studies have been conducted concerning the effects of religiosity on infertile women's mental status [11-13]. Khaani and Babakhani investigated the relationship between spiritual growth and perceived stress in 211 fertile women (106 subjects) and infertile women (105 subjects) in Tehran. The results demonstrated that happiness has a positive and statistically significant relationship with spirituality and a negative relationship with perceived stress in infertile women [14]. Naghibi et al. examined the relationship between spiritual well-being and mental health in 123 female patients under methadone maintenance treatment in Sari. The results indicated that the spiritual well-being score was $43 / 29$, and the mental health score was $41 / 26$. There was a statistically significant relationship observed between spiritual well-being and mental health [15].

Over the past twenty years, the extent and interest in investigating the relationship between mental health and quality of life in infertile women and spirituality have grown significantly, and awareness in this regard has increased among medical and psychiatric caregivers. Spiritual well-being is an important aspect of physical and mental health, and there is usually a positive relationship between religious beliefs, health outcomes and quality of life; therefore, spiritual understanding of patients is highly significant in the treatment process [16-18].

\section{Objectives}

People's mental health is dependent on time and the situation and is changeable according to living conditions. Considering the fact that fertility can affect various aspects of women's mental health and that in eastern countries, such as Iran, few studies have been carried out in this field, investigating the mental health of infertile women plays a decisive role in assessing the quality of healthcare systems provided to them. As there is a limited number of quantitative studies regarding mental health, spiritual well-being and quality of life in infertile women [19-22]. We designed this study to investigate the relationship between spiritual well-being, mental status and belief status.

Therefore, the objective of the present study was to explore the relationship between spiritual well-being in infertile women and their mental health and quality of life.

\section{Material and methods}

The current study was a cross-sectional, descriptive-analytic study. The inclusion criteria for the study consisted of: being Iranian and Muslim, having no known physical or mental illnesses, not smoking cigarettes or hookah, no drug addiction and having minimal skills of reading and writing, and the exclusion criteria for the study consisted of: the patient's unwillingness to cooperate. The statistical population of the study included infertile women referring to hospitals in Shiraz, among whom 247 subjects participated in the research.

\section{Ethical considerations}

The study was approved by the Shiraz University of Medical Sciences. Ethics committee code: CT-9371-7751.

\section{Research tool}

In the present research, the Palutzian \& Ellison 20-question spiritual well-being questionnaire was used, 10 questions of which measure religious well-being, and 10 questions measure existential well-being. The range of religious and existential well-being scores was 10-60 each. For sub-categories of religious and existential well-being, no rating and judgment are made on the basis of the score. The higher the score is, the higher the religious and existential well-being will be. The spiritual well-being score is the sum of these two sub-categories, with a range from 20-120. The answers to the questions were categorized from 'totally agree' to 'totally disagree' through a 6-point Likert scale. Spiritual well-being is divided into three levels of low 20-40, medium 41-99 and high 100-120. In a study by Fatemi et al., the validity of the spiritual well-being questionnaire was determined through content validity, and its reliability was determined through Cronbach's Coefficient Alpha 0.82 [23].

DASS-21 Questionnaire: Depression, Anxiety, Stress Scale [24], is a set of three self-reporting scales for evaluating negative emotional states encompassing depression, anxiety and stress. This scale is used to measure the severity of the main symptoms of depression, anxiety and stress. The validity and reliability of this questionnaire have been investigated by Samani et al. in Iran. Each of the DASS-21 subscales includes seven questions, and the final score of each one is obtained through the total score of the related questions. It is worth noting that the questionnaire includes scoring methods, interpretations and related tables [25].

QoL was then measured using the FertiQoL questionnaire. The study questionnaires gathered information about age, educational and economic status, type of medications, causes of infertility and duration of infertility. Interviews were also carried out by the researcher and a trained assistant in the infertility clinic. The objectives and contents of the study were explained to the participants when they were asked to fill out the questionnaires. QoL was measured in infertile couples by the internationally developed and validated FertiQoL questionnaire [26]. In this study, the Persian version of the FertiQoL survey was used. FertiQoL is a valid and reliable questionnaire for measuring infertile couples' QoL.

Data was presented as number (\%) for continuous and categorical variables, respectively. In this analysis, we used Spearman's correlation test, with two sides at a $5 \%$ level of significance, to investigate the correlation between continuous variables in the study. All the analyses were performed using the Statistical Package for Social Sciences (IBM SPSS Statistics for Windows, Version 22.0. Armonk, NY: IBM Corp).

\section{Results}

The results of Table 1 showed that 8 subjects out of 247 infertile women did not announce their ages. It was discovered that $49.8 \%$ of the subjects were 30 to 39 years old.

The results indicated that 97 subjects $(37.7 \%)$ were native to Shiraz, and the rest were non-native. In terms of education, 90 subjects (36.4\%) had diploma degrees, and $70 \%$ of the 173 subjects had a family of two members.

\begin{tabular}{|l|l|l|}
\hline \multicolumn{3}{|l|}{ Table 1. Descriptive statistics of the participants' age } \\
\hline Participant's age & Frequency & $\begin{array}{l}\text { Frequency percent- } \\
\text { age }\end{array}$ \\
\hline $20-29$ & 102 & 41.3 \\
\hline $30-39$ & 123 & 49.8 \\
\hline $40-49$ & 13 & 5.3 \\
\hline $50-59$ & 1 & 0.4 \\
\hline Total & 239 & 96.8 \\
\hline
\end{tabular}

The results of Table 2 showed that mental status has a statistically significant relationship with spiritual well-being ( $p=$ 0.001). Mental health has a statistically significant relationship with mental status $(p=0.001)$. There was a statistically signifi- 


\begin{tabular}{|l|l|l|l|l|l|l|}
\hline Table 2. Correlation results of research variables & $\begin{array}{l}\text { Spiritual well- } \\
\text {-being }\end{array}$ & Mental status & Mental health & Belief status & Economic status & Quality of life \\
\hline Spiritual well-being & - & & & & & \\
\hline Mental status & $0.001^{* *}$ & - & & & & \\
\hline Mental health & 0.82 & $0.001^{* *}$ & - & & & \\
\hline Belief status & $0.001^{* *}$ & 0.146 & $0.001^{* *}$ & - & & \\
\hline Economic status & 0.90 & 0.083 & 0.57 & $0.001^{* *}$ & - & \\
\hline Quality of life & 0.06 & $0.001^{* *}$ & $0.001^{* *}$ & $0.01^{* *}$ & 0.88 & \\
\hline
\end{tabular}

* Difference is significant at $0.1, * *$ difference is significant at 0.05 .

cant relationship achieved between belief status and spiritual well-being $(p=0.001)$. The relationship between belief status and mental health was statistically significant $(p=0.001)$. There was a statistically significant relationship between economic status and belief status $(p=0.001)$. Quality of life displayed a statistically significant relationship with mental status ( $p=$ 0.001). There was a statistically significant relationship achieved between quality of life and mental health $(p=0.001)$. The results also indicated that quality of life has a statistically significant relationship with belief status $(p=0.01)$.

To investigate the relationship between spiritual well-being and quality of life with mental and belief status, Pearson's correlation coefficient test was used. The results are summarized in the form of correlation coefficient and probability number in Table 3. As observed, there is a significant and direct relationship between mental status and belief status with spiritual well-being and the scores of mental status. For example, an increase in the levels of belief status lead to an increase in the levels of quality of life. A decrease in spiritual well-being also leads to a decrease in mental status.

\begin{tabular}{|c|c|c|c|c|}
\hline \multirow[t]{2}{*}{ Variable } & \multicolumn{2}{|c|}{ Mental status } & \multicolumn{2}{|c|}{ Belief status } \\
\hline & $\begin{array}{l}\text { Coeffi- } \\
\text { cient }\end{array}$ & $p$ & $\begin{array}{l}\text { Coeffi- } \\
\text { cient }\end{array}$ & $p$ \\
\hline \begin{tabular}{|l} 
Spiritual well- \\
-being
\end{tabular} & 0.54 & $<0.001$ & 0.229 & $<0.001$ \\
\hline Quality of life & 0.452 & $<0.001$ & 0.239 & $<0.01$ \\
\hline
\end{tabular}

\section{Discussion}

The results indicated that spiritual well-being has a statistically significant relationship with mental and belief status. There was a statistically significant relationship between mental health and mental and belief status as well. Quality of life also had a statistically significant relationship with mental status, mental health and belief status. Economic status indicated a statistically significant relationship with belief status only.

The results of the research are consistent with the study of Almasi et al. In this study, they compared spiritual well-being and quality of life infertile women (100 subjects) and infertile women (100 subjects) in llam. The results of their study demonstrated that spiritual well-being and quality of life in fertile women were better than those in infertile women. In the present study, it was also discovered that there is a statistically significant relationship between quality of life, mental health and belief status [27].

In different societies, infertility is a phenomenon that is associated with various psychological and emotional stresses, especially for women, and it affects all aspects of their lives. Since pregnancy, childbirth, breastfeeding and nursing are considered as women's affairs in the viewpoint of most people, women are again under accusation, and they suffer from a lot of stress in relation to infertility, especially when encountering failure in treatment. The fear of and concern about the spouse's reaction toward this problem and the fear of a collapse in the family are the first fears that make a woman do whatever it takes to escape from any failure in treatment. The love of being a mother, as well as the patriarchal beliefs for survival and the continuation of generation, lack of social and economic support for most women and little chance of remarriage for an infertile woman, on the one hand, and Iranians' disapproval of single life, on the other hand, are among the factors which double the hardships of infertility for women [28-30].

In their study, Mehrabi et al. investigated the relationship between spiritual well-being and quality of life in infertile women referring to the Isfahan Infertility Center. The results demonstrated that there was a statistically significant relationship between quality of life and spiritual well-being $(p<0.001)$; however, in the present study, no significant relationship between quality of life and spiritual well-being was indicated [31].

The present study discovered that there is a statistically significant relationship between quality of life and mental health in infertile women. Masoumi et al. investigated the prevalence of depression among Iranian fertile couples through a metaanalysis. The results indicated that depression is a major mental disorder that should be considered by obstetricians, and the outbreak of this problem reached from $44 \%$ in infertile couples through 2000-2005 to 50\% during 2006-2011. According to a report by the World Health Organization, depression will be the second leading cause of people's incapability by 2020; therefore, it is necessary to take preventive measures and make necessary policies [32].

In the current study, it was discovered that there is a statistically significant relationship between mental health and belief status.

In studies conducted at British and Iranian Infertility Clinics based on the experiences and priorities of Muslim and Christian infertile women, the role of religion and spirituality was investigated concerning various aspects of infertility, and evaluating the meaning of infertility with regard to religion, employing religious compromise strategies and the acquisition of religiouscentered power was seen to be in the central issue of "trust in a superior being" $[33,34]$. Religious infertile women perceived their problem as a strengthening experience for spiritual growth, and this view helped them obtain a sense of self-confidence and power to control their emotions. Religious infertile women attempted to adjust their attitudes through the following steps: optimism and positivity, having supportive relationships and gratefulness gratitude, offering spiritual compassion and choosing religious role models. They relied more on their own compromise strategies and less on official support sources, such as counseling services [33, 34].

\section{Conclusions}

In summary, it can be concluded that those who are responsible for consultation and the treatment of infertile women should consider religious and spiritual issues in addition to fo- 
cusing on the psychological needs of their patients. Stabilizing, compassionate communication with infertile women will allow them to discuss their religious views, which may eventually play a significant role in the success of their treatment process.

Spiritual well-being was correlated with the mental status of infertile women. Religious beliefs can be relevant to spiritual well-being, and if infertile women have appropriate mental health, their quality of life will increase.

The purpose of the present study was to investigate the relationship between spiritual well-being, mental health and quality of life in infertile women. In the future, it is suggested that research must be designed taking into account greater sample sizes, cultural differences, age-related distress and severity of psychological problems.

Acknowledgments. The authors would like to thank the Research Vice-chancellors of Shiraz University of Medical Sciences and the Infertility Research Center of Shiraz University of Medical Sciences for financially supporting the study.

Source of funding: This work was funded by the Shiraz University of Medical Sciences and the Infertility Research Center of Shiraz University of Medical Sciences. Project grant no.: 93-01-50-8933. Conflicts of interest: The authors declare no conflicts of interest.

\section{References}

1. Vitale SG, La Rosa VL, Rapisarda AMC, et al. Psychology of infertility and assisted re-productive treatment: the Italian situation. J Psychosom Obstet Gynecol 2017; 38(1): 1-3.

2. Deyhoul N, Mohamaddoost T, Hosseini M. Infertility-related risk factors: a systematic review. Int J Womens Health Reprod Sci 2017; 5(1): 24-29.

3. Canfield C, Taylor D, Nagy K, et al. Critical care nurses' perceived need for guidance in addressing spirituality in critically ill patients. Am J Crit Care 2016; 25(3): 206-211.

4. Romeiro J, Caldeira S, Brady V, et al. The spiritual journey of infertile couples: discussing the opportunity for spiritual care. Religions 2017; 8(4): 76.

5. Novak E. Berek \& Novak's gynecology. Philadelphia: Lippincott Williams \& Wilkins; 2007.

6. Parsanezhad ME, Jahromi BN, Zare N, et al. Epidemiology and etiology of infertility in Iran, systematic review and meta-analysis. Journal of Womens Health, Issues and Care 2013, doi: 10.4172/2325-9795.1000121.

7. Jahromi BN, Mansouri M, Forouhari S, et al. Quality of life and its influencing factors of couples referred to an infertility center in Shiraz, Iran. Int J Fertil Steril 2018; 11(4): 293-297.

8. Gana K, Jakubowska S. Relationship between infertility-related stress and emotional distress and marital satisfaction. J Health Psychol 2016; 21(6): 1043-1054.

9. Jayashankar V, Chaitanya R. A research study on female suicides due to infertility in Chit-toor, Andhra Pradesh from 2010 to 2016. Medico-Legal Update 2017; 17(2), doi: 10.5958/0974-1283.2017.00088.3.

10. Forouhari S, Ghaemi SZ. A survey of psychosexual disorders in infertile women referred to the Zeinabiee Infertility Center of Shiraz University of Medical Sciences. Res J Biol Sci 2013; 8(4): 99-103.

11. Tóth J. Common topics of sociology of religion in non-religion-specific journal articles. KOME: An International Journal of Pure Communication Inquiry 2017; 5(1): 121-146.

12. Romeiro J, Caldeira S, Brady V, et al. Spiritual aspects of living with infertility: synthesis of qualitative studies. J Clin Nurs 2017; 26(23$-24): 3917-3935$.

13. Chethana R. Treatment seeking pattern among infertile couples in a rural area. IJCMPH 2016; 3(10): 2884-2890.

14. Khani S, Babakhani N. Comparing the relation between spiritual growth and perceived stress with happiness among fertile and infertile women of Tehran City. Health Psychology 2017; 5(17): 95-108.

15. Naghibi SA, Ashari S, Rostami F, et al. Evaluation of the relationship between spiritual health and mental health in patients undergoing Methadone maintenance treatment. J Health Res Commun 2015; 1(3): 61-69.

16. Neely D, Minford EJ. Current status of teaching on spirituality in UK medical schools. Med Educ 2008; 42(2): 176-182.

17. Paloutzian RF, Park CL. Handbook of the psychology of religion and spirituality. New York: Guilford Publications; 2014.

18. Goker A, Yanikkerem E, Birge O, et al. Quality of life in Turkish infertile couples and related factors. Hum Fertil (Camb) 2018; 21(3): 195-203.

19. Namdar A, Naghizadeh MM, Zamani M, et al. Quality of life and general health of infertile women. Health Qual Life Outcomes 2017; 15(1): 139.

20. Boulet SL, Smith RA, Crawford S, et al. Health-related quality of life for women ever experiencing infertility or difficulty staying pregnant. Matern Child Health J 2017; 21(10): 1918-1926.

21. Kitchen $\mathrm{H}$, Aldhouse N, Trigg A, et al. A review of patient-reported out-come measures to assess female infertility-related quality of life. Health Qual Life Outcomes 2017; 15(1): 86.

22. Alijanpoor M, Omrani A, Ziraki A, et al. The relationship between spiritual well-being and life satisfaction in females with infertility. Women's Health Bulletin 2016; 3(4), doi: 10.17795/whb-32344.

23. Fatemi M, Nazari R, Safavi M. Relevance of spirituality for nurses on patient satisfaction with nursing care. J Med Ethics 2011; 5(17): 141-159.

24. Lovibond PF, Lovibond SH. The structure of negative emotional states: comparison of the Depression Anxiety Stress Scales (DASS) with the Beck Depression and Anxiety Inventories. Behav Res Ther 1995; 33(3): 335-343.

25. Samani S, Jokar B, Sahragard N. Effects of resilience on mental health and life satisfaction. IJPCP 2007; 13(3): $290-295$.

26. Karabulut A, Özkan S, Oğuz N. Predictors of fertility quality of life (FertiQoL) in infertile women: analysis of confounding factors. Eur J Obstet Gynecol Reprod Biol 2013; 170(1): 193-197.

27. Almasi M, Mahmoudiani S, Ghasemi T. Comparing spiritual health and quality of life among fertile and infertile women. IJN 2015; 28(93): 87-95.

28. Oats JJ, Abraham S. Llewellyn-Jones fundamentals of obstetrics and gynaecology. Elsevier Health Sciences; 2015.

29. Lucero SM, Pargament KI, Mahoney A, et al. Links between religious and spiritual coping and adjustment among fathers and mothers during first pregnancy. J Reprod Infant Psychol 2013; 31(3): 309-322.

30. Fido A. Emotional distress in infertile women in Kuwait. Int J Fertil Womens Med 2004; 49(1): 24-28.

31. Mehrabi T, Zeraki Dana A, Hosseini R, et al. A study on the relationship between spiritual wellbeing and quality of life in infertile women referred to infertility centers in Isfahan. The Journal of Urmia Nursing and Midwifery Faculty 2014; 12(7): 562-567.

32. Masoumi SZ, Poorolajal J, Keramat A, et al. Prevalence of depression among infertile couples in Iran: a meta-analysis study. Iranian J Public Health 2013; 42(5): 458-466. 
33. Latifnejad Roudsari R, Allan H, Smith P. A qualitative inquiry into the mediating role of religion and spirituality in adjusting marital relationships of infertile women. JMRH 2013; 1(1): 33-41.

34. Roudsari RL, Allan HT. Women's experiences and preferences in relation to infertility coun-selling: a multifaith dialogue. Int J Fertil Steril 2011; 5(3): 158-167.

Tables: 3

Figures: 0

References: 34

Received: 10.05 .2020

Reviewed: 20.05.2020

Accepted: 01.09.2020

Address for correspondence:

Sedighe Forouhari, MA, PhD

Infertility Research Center

Research Center of Quran, Hadith and Medicine

Shiraz University of Medical Sciences,

Shiraz

Iran

Tel.: +98 9176352435

E-mail: atefehzare@protonmail.com 